\title{
Regadenoson in heart transplant recipients: Use without worries
}

\author{
Mouaz H. Al-Mallah, MS, MSc ${ }^{a}$ \\ a Houston Methodist DeBakey Heart \& Vascular Center, Houston Methodist Hospital, Houston, \\ TX
}

Received Oct 9, 2018; accepted Oct 10, 2018

doi: $10.1007 / \mathrm{s} 12350-018-01490-1$

\section{See related article, pp. 943-948}

Cardiac allograft vasculopathy (CAV), a generalized coronary vasculopathy, is one of the leading causes of death post cardiac transplant. Thus, its detection is important from a diagnostic and prognostic standpoint to identify those transplant patients at risk of graft loss and poor outcomes. ${ }^{1}$ However, screening for $\mathrm{CAV}$ in routine clinical practice is variable. There are no clear unified guidelines on how to detect this vasculopathy and manage it. Often treatment providers utilize coronary angiography as the test of choice to detect CAV and guide management and assess therapeutic responses. Myocardial perfusion imaging (MPI) has been suggested as a tool that can provide diagnostic and prognostic value. However, there have been several concerns about the use vasodilator stress in this patient population. This is in part due to the fact that the denervated sinus and atrioventricular nodes of the transplanted hearts have exaggerated responses to sympathomimetic amines. ${ }^{2} \mathrm{~A}$ few single-center studies have suggested that adenosine in this patient population have acceptable risk. In a single-center study of adenosine MPI in transplant patients, adenosine infusion was found to be associated with a higher incidence of sinus pauses (4.9\% vs $0 \%$ ), second $(11.8 \%$ vs $4.9 \%)$ and third degree AVBs $(2.9 \%$ vs $0 \%$ ) compared to the nontransplant patients. However, only $2 \%$ of the studies were terminated due to bradyarrythmia. It is important to note that baseline right

Reprint requests: Mouaz H. Al-Mallah, MS, MSc, Houston Methodist DeBakey Heart \& Vascular Center, Houston Methodist Hospital, 6565 Fannin Street, Smith-19, Houston, TX 77030; mouaz74@gmail.com

J Nucl Cardiol 2020;27:949-51.

$1071-3581 / \$ 34.00$

Copyright (C) 2018 American Society of Nuclear Cardiology. or left bundle branch block, beta-blockers, calcium blockers, or digoxin were not associated with occurrence of AVB. ${ }^{3}$

However, there has been a shift toward the use of regadenoson in most nuclear cardiology laboratories given its improved tolerance and enhanced safety profile. ${ }^{4-6}$ However, the safety of regadenoson in transplant recipients has not been well documented. A singlecenter study assessed the safety and tolerability of regadenoson in 40 orthotropic heart transplant patients. Both adenosine and regadenoson had similar side-effect profiles,. and there were no episodes of bradycardia and/ or AV block with regadenoson. However, that study was limited by small sample size. ${ }^{7}$ (Table 1 ).

In this issue of the journal, Lazarus et $\mathrm{al}^{8}$ retrospectively report on the safety of regadenoson use in 123 orthotropic heart transplant patients who underwent positron emission tomography (PET) stress testing using rubidium imaging. The investigators evaluated the hemodynamics and ECG response as well as patient response and adverse events in response to regadenoson. As reported before, regadenoson was associated with increase in the heart rate and a drop in systolic, diastolic, and mean blood pressures. Of note, a larger proportion of OHT patients had hypotension (12\%), but a similar proportion of OHT patients experienced large decreases in blood pressure ( $>35 \mathrm{mmHg} ; 24 \%$ vs $29 \%$ ) Impotently, there were no documented second and third degree AV blocks. The authors concluded that regadenoson is safe in patients with prior heart transplantation.

This is the largest series of orthotropic heart transplant patients who underwent vasodilator or specifically regadenoson stress testing. These results have to be interpreted in the context used. Regadenoson was injected as per advised protocol. Almost none of the patients has any baseline heart block. In addition, beta blockers were stopped 24 hours prior to the stress test unless these patients had a myocardial infarction within the last three years or had systolic dysfunction that 
Table 1. Comparison of the safety of vasodilator stress in patients with heart transplant patients

\begin{tabular}{lccc}
\hline & Al-Mallah et $\mathbf{a l}^{\mathbf{3}}$ & Cavalcante et $\mathbf{~ a l}^{\mathbf{7}}$ & ${\text { Lazarus et } \mathbf{a l}^{\mathbf{8}}}$ \\
\hline Vasodilator & Adenosine & Regadenoson & Regadenoson \\
Number of patients & 102 & 40 & 123 \\
Second degree AV block & $11.8 \%$ & $0 \%$ & $0 \%$ \\
Third degree AV block & $2.9 \%$ & $0 \%$ & $0 \%$ \\
Sinus pauses & $4.9 \%$ & $2 \%$ & $0 \%$
\end{tabular}

Table 2. Adverse events of Regadenoson in patients with heart transplant in comparison to the general population

\begin{tabular}{|c|c|c|c|}
\hline & $\begin{array}{c}\text { Heart transplant } \\
\text { patients }^{8}(\%)\end{array}$ & $\begin{array}{c}\text { Heart transplant } \\
\text { patients }^{7}(\%)\end{array}$ & $\begin{array}{l}\text { ADVANCE } \\
\text { registry }^{6}(\%)\end{array}$ \\
\hline Dyspnea & 67 & 68 & 25 \\
\hline Nausea & 12 & 36 & 6 \\
\hline Flushing & 12 & 12 & 17 \\
\hline Chest discomfort & 3 & 19 & 11 \\
\hline Headache & 3 & 21 & 29 \\
\hline Dizziness/lightheadedness & 5 & 19 & 7 \\
\hline
\end{tabular}

requires beta blocker therapy. It is interesting to note that in the few patients who used beta-blocker therapy, there was no effect on the heart rate or the presence of pauses. Most of these patients have presented more than five years after transplant. Thus, the safety of regadenoson in patients with transplants less than this duration is not known and regadenoson should be used carefully in this subgroup of transplant patients.

It is important to note that this study does indicate a lower incidence of headache and a significantly higher incidence of dyspnea in the heart transplant population compared to the nontransplant patients included in different registries and randomized controlled trial. ${ }^{8}$ (Table 2) The etiology of this dyspnea is unknown and no obvious pharmacologic interaction between immunosuppression medications and regadenoson. This finding of increased dyspnea is not unique to this study and has been described before. ${ }^{7}$ (Table 2)

These results are reassuring and will be reassuring to providers who refer transplant patients MPI for the assessment of possible transplant CAV. In the current practice, many patients are referred to invasive coronary angiography directly. For example, in the study institution, since 2006, approximately 350 adult patients have undergone heart transplantation. PET stress imaging, dobutamine stress echocardiography, and coronary angiography are used to screen for coronary angiography based on patient comorbid conditions and physician preference. Of these 350 heart transplant patients, only 150 of these patients $(40 \%)$ have undergone a total of 319 PET studies during the study period. This variation in practice patterns is due to many factors including patients' preferences, practitioners' preferences as well as renal function status.

In addition, there is also ambiguity among clinical practice guidelines on the best way to assess for CAV. In addition to the technique mentioned above. There is growing evidence is for coronary computed tomography to detect CAV. ${ }^{9}$ In a study of 138 patients, the patient level sensitivity, specificity, and positive and negative predictive values of $98 \%, 78 \%, 77 \%$, and $98 \%$, respectively, for diagnosis of CAV with any degree of stenosis. None of the 61 patients with normal cardiac CT angiographic results had CAV on the basis of invasive angiography images. ${ }^{10}$ A meta-analysis of 13 studies evaluating 615 patients showed patient-based analyses comparing CCTA versus angiography for the detection of any CAV ( $>$ luminal irregularities) and significant CAV (stenosis $\geq 50 \%$ ), showed mean weighted sensitivities of $97 \%$ and $94 \%$, specificities of $81 \%$ and $92 \%$, a 
negative predictive value of $97 \%$ and $99 \%$, a positive predictive value of $78 \%$ and $67 \%$, and diagnostic accuracies of $88 \%$ and $94 \%$, respectively. ${ }^{11}$ However, CT angiography is limited by the need to control the heart rate. It cannot be safely performed in patients with renal insufficiency, a common co-morbidity in heart transplant patients. ${ }^{9}$

PET also allows for comprehensive assessment of patients with suspect CAV. In addition to accurate stenosis assessment, coronary flow reserve assessment is helpful in these patients. In a study of 40 transplant recipients undergoing invasive adenosine hemodynamics and dipyridamole rubidium PET, CAV was detected in 32 patients $(80 \%)$ by intravascular ultrasound. PET derived coronary flow reserve correlated significantly with invasive coronary flow reserve assessment and fractional flow reserve. Patients with CAV or microvascular dysfunction had reduced coronary flow reserve and stress myocardial blood flow. ${ }^{12,13}$ The sensitivity, specificity, positive, and negative predictive value of semiquantitative PET perfusion alone for detecting moderate-to-severe CAV were 83\% [52-98], $82 \%$ [69-91], 50\% [27-73], and 96\% [85-99], respectively. ${ }^{14}$ Coronary flow reserve also adds prognostic value in this patient population. In 94 heart transplant recipients undergoing vasodilator PET, the annualized event rate was $5 \%, 9 \%$, and $25 \%$ in patients with normal, mildly, and moderate-to-severely abnormal PET CAV grading $(P<0.001)$, respectively. ${ }^{14}$

With the current study, the data are now available to confirm the safety of PET MPI and allow the clinicians to utilize this important tool in the care of these patients. As many of these patients require frequent screening for CAV, regadenoson PET appear to be the ideal test with the maximum safety profile and optimal risk stratification.

\section{Disclosure}

The author has no conflict of interest to disclose.

\section{References}

1. Pollack A, Nazif T, Mancini D, Weisz G. Detection and Imaging of Cardiac Allograft Vasculopathy. JACC Cardiovascr Imaging. 2013;6:613-23.

2. Ellenbogen KA, Thames MD, DiMarco JP, Sheehan H, Lerman BB. Electrophysiological effects of adenosine in the transplanted human heart. Evidence of supersensitivity. Circulation. 1990;81:821-8.

3. Al-Mallah MH, Arida M, Garcia-Sayan E, Assal C, Zegarra GT, Czerska B, Ananthasubramaniam K. Safety of adenosine pharmacologic stress myocardial perfusion imaging in orthotopic cardiac transplant recipients: a single center experience of 102 transplant patients. Int J Cardiovasc Imaging. 2011;27:1105-11.

4. Mahmarian JJ, Peterson LE, Xu J, Cerqueira MD, Iskandrian AE, Bateman TM. Thomas GS and Nabi FJJoNC. Regadenoson provides perfusion results comparable to adenosine in heterogeneous patient populations: A quantitative analysis from the ADVANCE MPI trials. 2015;22:248-61.

5. Mahmarian JJ, Cerqueira MD, Iskandrian AE, Bateman TM, Thomas GS, Hendel RC, Moye LA, Olmsted AW. Regadenoson induces comparable left ventricular perfusion defects as adenosine. A quantitative analysis from the ADVANCE MPI 2 Trial. JACC Cardiovasc Imaging. 2009;2:959-68.

6. Iskandrian AE, Bateman TM, Belardinelli L, Blackburn B, Cerqueira MD, Hendel RC, Lieu H, Mahmarian JJ, Olmsted A, Underwood SR, Vitola J, the AMPII. Adenosine versus regadenoson comparative evaluation in myocardial perfusion imaging: Results of the ADVANCE phase 3 multicenter international trial. J Nucl Cardiol. 2007;14:645-58.

7. Cavalcante JL, Barboza J, Ananthasubramaniam K. Regadenoson is a safe and well-tolerated pharmacological stress agent for myocardial perfusion imaging in post-heart transplant patients. J Nucl Cardiol. 2011;18:628-33.

8. Lazarus JJ, Saleh A, Ghannam M, Aaronson K, Colvin M, Pagani F, Koelling T, Corbett JR, Weinberg RL, Murthy VL, Konerman MC. Safety of Regadenoson positon emission tomography stress testing in orthotopic heart transplant patients. J Nucl Cardiol. 2018. https://doi.org/10.1007/s12350-016-0734-6.

9. Al-Mallah MH, Aljizeeri A, Villines TC, Srichai MB, Alsaileek A. Cardiac computed tomography in current cardiology guidelines. J Cardiovasc Comput Tomogr. 2015;9:514-23.

10. Mittal TK, Panicker MG, Mitchell AG, Banner NR. Cardiac allograft vasculopathy after heart transplantation: electrocardiographically gated cardiac CT angiography for assessment. Radiology. 2013;268:374-81.

11. Wever-Pinzon O, Romero J, Kelesidis I, Wever-Pinzon J, Manrique C, Budge D, Drakos SG, Piña IL, Kfoury AG, Garcia MJ, Stehlik J. coronary computed tomography angiography for the detection of cardiac allograft vasculopathy: A meta-analysis of prospective trials. J Am Coll Cardiol. 2014;63:1992-2004.

12. Chih S, Chong AY, Erthal F, deKemp RA, Davies RA, Stadnick E, So DY, Overgaard C, Wells G, Mielniczuk LM, Beanlands RSB. PET assessment of epicardial intimal disease and microvascular dysfunction in cardiac allograft vasculopathy. J Am Coll Cardiol. 2018;71:1444-56.

13. Chih S, Chong AY, Mielniczuk LM, Bhatt DL, Beanlands RS. Allograft vasculopathy: the Achilles' heel of heart transplantation. J Am Coll Cardiol. 2016;68:80-91.

14. Bravo PE, Bergmark BA, Vita T, Taqueti VR, Gupta A, Seidelmann S, Christensen TE, Osborne MT, Shah NR, Ghosh N, Hainer J, Bibbo CF, Harrington M, Costantino F, Mehra MR, Dorbala S, Blankstein R, Desai A, Stevenson L, Givertz MM, Di Carli MF. Diagnostic and prognostic value of myocardial blood flow quantification as non-invasive indicator of cardiac allograft vasculopathy. Eur Heart J. 2018;39:316-23. 